\title{
Comparative study on differences of the maximal strength, isokinetic knee and trunk functions and anaerobic capacity according to the position in college and professional rugby players
}

\author{
Yeong-Hyun Cho, Ji-Hee Park, Ji-Eun Kim, Joo-In Yu, Young-Pyo Kim, Tae-Beom Seo* \\ Department of Kinesiology, College of Natural Science, Jeju National University
}

\begin{abstract}
[Purpose] The purpose of this study is to compare the maximal strength, isokinetic muscle function and anaerobic capacity according to the position of college and professional rugby players. [Methods] Subjects for this study were 54 athletes and randomly divided into 4 groups: the forwards group in college rugby players (FCRP, $n=10$ ), backs group in college rugby players (BCRP, $n=16$ ), forwards group in professional rugby players (FPRP, $n=16$ ), and backs group in professional rugby players (BPRP, $n=12$ ). Physical fitness was consisted of squat, bench press, bilateral grip strength. Isokinetic knee and trunk muscle functions were measured by Humac Norm device, and anaerobic pedaling power was analyzed by Wingate test. Significant differences between groups were determined with one-way repeated ANOVA. [Results] As the result of this study, there was no statistically significant difference between the absolute and relative values of the squat and bilateral grip strengths, but bench press was significantly higher in FPRP and BPRP compared to other groups. Isokinetic knee and trunk extensor and flexor muscle strength showed stronger in FPRP and BPRP than those in FCRP and BCRP. In addition, the anaerobic pedaling power was also the highest in FPRP and BPRP. [Conclusions] Our findings suggest important information that the college rugby players and forwards in professional rugby team should be given scientific training to improve their maximum strength, isokinetic strength and anaerobic power.
\end{abstract}

Key words: Rugby, Isokinetic, Anaerobic capacity, Physical fitness

\section{서 론 \\ 럭비는 8명의 포워드(forwards)와 7명의 백스(backs) 총 15 명으로 구성되고, 경기 방식은 상대와 몸을 부딪치며 공격과 수비가 진행되는 충돌형 스포츠이다. 구체적으로 포워드는 스크럼 (scrum), 럭(ruck), 몰 (maul)과 같은 방 어 기술과 함께 공격에 가담해야 하는 특성상 큰 체격과 높은 근력이 요구되고, 백스는 빠르게 움직여 상대의 수}

논문 투고일 : 2019. 04. 30.

논문 수정일 : 2019. 05. 12 .

게재 확정일 : 2019. 05. 16.

* 교신저자 : 서태범(soetb@jejunu.ac.kr).

* 본 연구는 2018년도 교육부의 재원으로 한국연구재단-국립대

육성사업의 지원을 받아 수행된 연구임.
비를 피해 득점을 해야 하므로 스피드와 민첩성 등이 필 요하다(Duthie et al., 2003; Lindasy et al., 2015). 그러 므로 럭비 지도자들은 선수의 경기력 향상을 위한 훈련 프로그램 구축 시 포지션에 따른 체격과 체력의 차이를 이해할 필요가 있다(Jones et al., 2015).

럭비경기는 전·후반 각각 40 분씩 총 80 분 동안 진행 되며, 경기 종료 시점까지 포워드와 백스 선수들은 4 6 초 동안 달리고 쓰러지는 고강도의 퍼포먼스 상황이 자 주 발생한다(Cunniffe et al., 2009). 이러한 고강도 퍼포 먼스는 짧은 시간에 폭발적인 힘을 발휘하는 근수축력 (strength of muscle contraction)과 스피드와 밀접한 관련이 있으며, 운동생리학적으로는 무산소성 파워 ( $\mathrm{an}^{-}$ aerobic power)로 정의할 수 있다(Serresse et al., 1989). 
경기력과 관련한 선행연구를 살펴보면, 럭비와 같은 고 강도의 충돌 스포츠는 최대근력 (90 100\% 1RM) 및 플라이오메트릭 훈련과 함께 무산소성 파워를 향상시킬 수 있는 고강도의 단거리 인터벌 트레이닝 (short highintensity interval training)이 경기력을 향상시킬 수 있다 고 보고하였다(Comfort et al., 2011; Pienaar \& Coetzee, 2013; Dymond et al., 2011). 일반적으로 운동선수들의 무산소성 파워 능력은 윈게이트 검사(Wingate test)를 통해 측정되며, 선수들의 최대파워 (peak power)와 평균 파워 (average power)를 확인할 수 있다. 또한 무산소성 파워는 포워드와 백스 선수들에 경기력 향상과 자신의 팀 승리를 위해 반드시 필요한 체력요인이다(Franchini et al., 2011; Quarrie \& Wilson, 2000; Ueno et al., 2011; Zagatto et al., 2009).

무산소성 파워와 함께 최대근력은 럭비 선수들에게 중요한 체력 요인 중에 하나이다. 특히 포워드 선수들은 상대의 공격을 몸으로 막아내야 하기 때문에 대둔근 $\left(\mathrm{glu}^{-}\right.$ teus maximus), 대퇴사두근(quadriceps), 햄스트링 (hamstring) 및 척추기립근(spinal erector muscle)과 같은 무 릎과 코어 근육의 최대근력이 상당히 중요하다. 뿐만 아 니라 백스 선수들도 순간적인 스피드와 방향 전환을 위해 속근(fast twitch fibers)의 최대근력과 효율적인 동원이 수반되어야 한다(Monica et al., 2016). 럭비 선수의 포지 션에 따라 대퇴사두근과 햄스트링의 최대근력이 통계적 으로 유의한 차이가 있고, 허리 근기능이 높은 선수들일 수록 경기력이 우수하다고 하였다(Davies \& Kaar, 1993; Mendiguchia et al., 2015). Brown et al.(2014)는 운동 선수들의 각 관절에 신전(extension)과 굴곡(flexion)시 발생하는 최대근력과 주동근과 길항근의 동측 근력 비 율의 차이는 등속성 장비로 분석 가능하다고 보고하였다.

이러한 선행연구들을 종합해 보면, 럭비 선수들의 포 지션별 경기력 관련 체력요인들에 차이는 알 수 있지만, 선수층이 얇아 대학과 실업팀이 같은 리그에 참여하는 우 리나라 럭비 리그 특성상, 실업팀 입단을 위해 대학 선수 들에게 요구되는 구체적인 경기력 관련 정보를 제 공하는 연구는 부족한 실정이다. 또한 럭비관련 국내 선행연구는 운동역학적 분석과 심리학적요인을 통한 경기력 향상에 만 초점을 맞추고 있는 실정이다. 따라서 본 연구에서는 대학과 실업 럭비팀의 포지션별 체격, 최대근력, 등속성 무릎과 허리 근기능 및 무산소성 파워를 비교하여 집단 간의 차이를 확인하고, 향후 대학선수들의 경기력 향상을
위한 트레이닝 프로그램 수립에 필요한 기초자료를 제 공하고자 한다.

\section{연구방법}

\section{연구대상}

본 연구는 대학 및 실업 럭비 남자선수 총 54 명으로, 실험에 참여하는데 신체적 제한이 없는 선수들로 구성하 였다. 실험 전 모든 대상자들은 연구에 대한 설명을 듣고, 참가 동의서를 작성하였다. 본 연구의 집단은 대학 럭비 선수 26명중 전위 (forwards in college rugby players, FCRP) 10명과 후위 (backs in college rugby players, $\mathrm{BCRP}$ ) 16명, 실업 럭비선수 28명중 전위 (forwards in professional rugby players, FPRP) 16명과 후위(backs in professional rugby players, BPRP) 12 명으로 총 4 그룹 으로 분류하였다. 연구대상자의 특성은 〈Table 1)과 같다.

Table 1. Physical characteristics of the subjects

$(\mathrm{Mean} \pm \mathrm{SD})$

\begin{tabular}{lcccc}
\hline \hline Variable & FCRP $^{1}$ & BCRP $^{2}$ & FPRP $^{3}$ & BPRP $^{4}$ \\
\hline Height $(\mathrm{cm})$ & $183.6 \pm 4.8$ & $180.6 \pm 3.2$ & $183.1 \pm 4.2$ & $179.6 \pm 6.9$ \\
\hline Weight(kg) & $110.4 \pm 9.4$ & $85.9 \pm 8.3$ & $109.9 \pm 10.8$ & $86.3 \pm 10.1$ \\
\hline Age(yr) & $19.9 \pm 1.0$ & $20.1 \pm 1.5$ & $25.0 \pm 1.7$ & $25.1 \pm 2.2$ \\
\hline \hline
\end{tabular}

$\overline{\text { FCRP }^{1} \text {, forwards in college rugby players; } \mathrm{BCRP}^{2} \text {, backs }}$ in college rugby players: $\mathrm{FPRP}^{3}$, forwards in professional rugby players: $\mathrm{BPRP}^{4}$, backs in professional rugby players.

\section{측정 항목 및 방법}

\section{신체구성}

대상자들은 8시간 공복을 유지한 상태에서 오전 9시까 지 실험실에 방문하였고, 가벼운 의복과 신발을 착용하지 않은 상태에서 자동신장체중 측정기(DS-103M, Dong Sahn Jenix, Seoul, Korea)를 사용하여 신장과 체중을 측 정하였다. 제지방량(fat-free mass; FFM), 체지방률(body fat percentage; \%fat), 체질량지수(body mass index; $\mathrm{BMI}$ )과 같은 신체구성은 Inbody 770(Inbody 770, 
Inbody, Seoul, Korea)으로 측정하였다.

\section{최대근력 측정}

최대근력 측정 변인은 스쿼트(squat), 벤치프레스(bench press), 좌·우 악력 (grip strength)으로 구성하였다. 스쿼 트와 벤치프레스는 Ariel(16120 Smith Press, Cybex, Wedway, USA)를 사용하여 최대근력의 절대값과 체중으 로 환산한 상대값을 제시하였고, 악력 (Tachometer, TKK 5401, Takei, Japan) 측정은 좌·우측에서 2회씩 측정하 여 최고치를 기록하였다.

\section{등속성 무릎 및 허리 근력 측정}

무를과 허리의 등속성 근력은 HUMAC NORM(Humac Norm 776, CSMi, Boston, USA)을 사용하여 측정하였다. 등속성 무릎 굴곡과 신전 검사(isokinetic knee flexion and extension test)는 대퇴사두근과 햄스트링의 근력을 측정하는 방법이고, 무릎의 관절가동범위는 $0 \sim 90^{\circ}$, 각속 도는 $60^{\circ} / \mathrm{sec}$ 로 설정하여 수행하였다. 또한 등속성 허리 굴곡과 신전 검사(isokinetic trunk flexion and extension test)는 코어 근력을 측정하는 방법으로, 관절가동 범위는 $-10 \sim 70^{\circ}$, 각속도는 $30^{\circ} / \mathrm{sec}$ 로 설정하여 절대값 과 상대값(절대값/체중* 100 )을 제시하였다. 등속성 검사 전 모든 대상자는 부상의 위험을 최소화하기 위해 무릎 과 허리의 굴곡과 신전 준비운동을 각각 5 회 수행하였다.

\section{윈게이트 검사}

무산소성 파워 측정은 Monark bicycle (Ergomedic 823E, Monark Exercise AB, Vansbro, Sweden)을 사용 하여 30 초 동안 최대페달링을 수행하는 윈게이트 검사를 수행하였다. 윈게이트 검사 시 부하는 체중당 $0.075 \mathrm{kp}$
로 설정하였고, 3 분동안 가벼운 페달링 후 설정된 부하로 최대속도가 되었을 때부터 '시작' 신호와 함께 30초 동안 최대페달링을 유지하였다. 윈게이트 검사 결과는 최대파 워 (peak power)와 평균파워 (average power)의 절대값 과 상대값으로 제시하였다.

\section{통계 처리}

본 연구의 자료처리는 IBM SPSS Statistics 22.0 프 로그램을 사용하여 그룹간 체력관련요인과 등속성 무릎 및 허리의 차이를 확인하였다. 그룹간 차이를 검정하기 위하여 일원배치 분산분석(One-way repeated ANOVA) 를 사용하였고, Scheffe HSD를 통해 사후 검증을 실시하 였다. 통계적 유의수준은 $\alpha=.05$ 로 설정하였다.

\section{연구결과}

\section{포지션별 신체구성의 변화}

대학 및 실업 럭비선수들의 포지션별 신체구성은 〈Table $2>$ 와 같다. 체질량지수(BMI), 제지방량 $(\mathrm{FFM})$, 체지방 률 $(\% \mathrm{Fat})$ 은 모든 집단에서 유의한 차이가 나타났다 $(p$ < .001). 사후 검증 결과 $\mathrm{BMI}, \mathrm{FFM}, \% \mathrm{Fat}$ 는 FCRP, FPRP 그룹이 $\mathrm{BCRP}, \mathrm{BPRP}$ 그붑보다 높은 것으로 나타났다.

\section{포지션별 최대근력의 변화}

대학 및 실업 럭비선수들의 포지션별 최대근력을 측정 한 결과는 〈Table 3〉과 같다. 스쿼트의 절대값과 상대값 그리고 좌·우 악력은 통계적으로 유의한 차이가 나타나지

Table 2. The different of body composition

$(\mathrm{Mean} \pm \mathrm{SD})$

\begin{tabular}{lllllll}
\hline \hline Variable & FCRP & BCRP & FPRP $^{3}$ & BPRP $^{4}$ & F-value & Scheffe \\
\hline BMI $\left(\mathrm{kg} / \mathrm{m}^{2}\right)$ & $32.8 \pm 3.0$ & $26.4 \pm 3.0$ & $32.8 \pm 3.2$ & $26.7 \pm 1.6$ & $22.694^{* * *}$ & $2,4<1,3$ \\
\hline FFM $(\mathrm{kg})$ & $82.8 \pm 5.7$ & $70.3 \pm 5.6$ & $83.9 \pm 7.3$ & $70.9 \pm 6.2$ & $18.896^{* * *}$ & $2,4<1,3$ \\
\hline \% Fat & $24.7 \pm 4.9$ & $17.9 \pm 3.2$ & $24.0 \pm 3.7$ & $15.9 \pm 2.3$ & $19.501^{* * *}$ & $4,2<3,1$ \\
\hline \hline
\end{tabular}

$\overline{\mathrm{FCRP}^{1}}$, forwards in college rugby players; $\mathrm{BCRP}^{2}$, backs in college rugby players; $\mathrm{FPRP}^{3}$, forwards in professional rugby players; BPRP 4 , backs in professional rugby players; BMI, body mass index; FFM, free fat mass; \%Fat, body fat percentage.

${ }^{*} p<.05^{* *} p<.01^{* *} p<.001$ 
않았지만, 벤치프레스는 절대값 $(p<.001)$ 과 상대값 $(p<.01)$ 에서 유의한 차이가 나타났다. 사후 검증 결과 벤치프레스 절대값은 $\mathrm{BPRP}, \mathrm{FPRP}$ 그룹이 $\mathrm{BCRP}$ 그룹보다 높은 것 으로 나타났으며, 상대값은 $\mathrm{BPRP}$ 그룹이 $\mathrm{FCRP}, \mathrm{BCRP}$ 그룹보다 높은 것으로 나타났다.

\section{포지션별 등속성 무릎 근기능의 변화}

대학 및 실업 럭비 선수들의 포지션별 무릎 등속성 근 기능을 측정한 결과는 〈Table 4〉와 같다. 우신근의 절대
값 $(p<.021)$ 과 상대값 $(p<.007)$, 우굴근의 절대값 $(p<.01)$ 과 상대값 $(p<.001)$ 은 그룹간에 유의한 차이가 나타났다. 좌신근 절대값 $(p<.022)$ 과 상대값 $(p<.001)$, 좌굴근 상 대값 $(p<.001)$ 은 통계적으로 유의한 차이가 나타났지만, 좌굴근 절대값은 유의한 차이가 나타나지 않았다. 신근 과 굴근 좌우비에서는 유의한 차이가 나타나지 않았다. 우측 굴곡과 신전 비율 $(p<.026)$, 좌측 굴곡과 신전 비율 ( $p<.025)$ 은 유의한 차이가 나타났다. 사후 검증 결과 우 신근 절대값은 $\mathrm{FPRP}$ 그룹이 $\mathrm{BCRP}$ 그룹보다 높은 것으로 나타났고, 상대값에서는 $\mathrm{BPRP}$ 그룹이 $\mathrm{FCRP}$ 그룹보다 높은

Table 3. The different of fitness level

(Mean $\pm \mathrm{SD})$

\begin{tabular}{lcccccc}
\hline \hline Variable & FCRP $^{1}$ & BCRP $^{2}$ & FPRP $^{3}$ & BPRP $^{4}$ & F-value & Scheffe \\
\hline Squat $(\mathrm{kg})$ & $200.1 \pm 25.8$ & $195.3 \pm 21.4$ & $206.6 \pm 34.8$ & $199.0 \pm 19.8$ & .492 & .211 \\
\hline Squat $(\mathrm{kg} / \mathrm{kg})$ & $1.1 \pm 0.2$ & $1.1 \pm 0.1$ & $1.1 \pm 0.2$ & $1.1 \pm 0.1$ & $2<.838^{* * *}$ & $2<4,3$ \\
\hline Bench press $(\mathrm{kg})$ & $104.4 \pm 20.5$ & $88.3 \pm 16.6$ & $119.8 \pm 17.0$ & $109.9 \pm 12.7$ & 1.3 & \\
\hline Bench press $(\mathrm{kg} / \mathrm{kg})$ & $1.0 \pm 0.2$ & $1.0 \pm 0.2$ & $1.1 \pm 0.1$ & $1.3 \pm 0.3$ & $6.505^{* *}$ & $1,2<4$ \\
\hline Right Grip strength $(\mathrm{kg})$ & $52.9 \pm 5.5$ & $52.7 \pm 7.3$ & $55.5 \pm 11.4$ & $51.8 \pm 6.9$ & .530 & \\
\hline Left Grip strength $(\mathrm{kg})$ & $53.6 \pm 7.1$ & $53.5 \pm 6.4$ & $56.5 \pm 8.6$ & $50.0 \pm 3.4$ & 2.108 & \\
\hline
\end{tabular}

$\mathrm{FCRP}^{1}$, forwards in college rugby players; $\mathrm{BCRP}^{2}$, backs in college rugby players; $\mathrm{FPRP}^{3}$, forwards in professional rugby players: $\mathrm{BPRP}^{4}$, backs in professional rugby players.

${ }^{*} p<.05^{* *} p<.01^{* *} p<.001$

Table 4. Isokinetic knee strength at $60 \% \mathrm{sec}$

$(\mathrm{Mean} \pm \mathrm{SD})$

\begin{tabular}{lcccccc}
\hline \hline Variable & FCRP & BCRP & FPRP & BPRP & F-value & Scheffe \\
\hline Right extension $(\mathrm{N} \cdot \mathrm{m})$ & $262.1 \pm 43.7$ & $235.3 \pm 33.2$ & $285.9 \pm 50.4$ & $256.7 \pm 47.2$ & $3.539^{*}$ & $2<3$ \\
\hline Right extension $(\% \mathrm{BW})$ & $239.3 \pm 46.3$ & $274.1 \pm 30.5$ & $260.4 \pm 40.5$ & $296.0 \pm 34.2$ & $4.510^{*}$ & $1<4$ \\
\hline Right flexion $(\mathrm{N} \cdot \mathrm{m})$ & $131.1 \pm 22.8$ & $134.9 \pm 23.9$ & $166.6 \pm 24.9$ & $142.3 \pm 24.9$ & $6.322^{* *}$ & $1,2<3$ \\
\hline Right flexion $(\% \mathrm{BW})$ & $119.6 \pm 22.7$ & $157.1 \pm 22.9$ & $152.4 \pm 23.1$ & $164.4 \pm 16.0$ & $9.020^{* * *}$ & $1<3,2,4$ \\
\hline Left extension $(\mathrm{N} \cdot \mathrm{m})$ & $258.7 \pm 43.3$ & $231.8 \pm 32.8$ & $280.9 \pm 51.4$ & $267.2 \pm 46.9$ & $3.520^{*}$ & \\
\hline Left extension $(\% \mathrm{BW})$ & $235.6 \pm 40.5$ & $270.7 \pm 34.7$ & $256.1 \pm 44.5$ & $308.8 \pm 37.0$ & $7.046^{* * *}$ & $1,3<4$ \\
\hline Left flexion $(\mathrm{N} \cdot \mathrm{m})$ & $131.7 \pm 24.3$ & $135.3 \pm 13.4$ & $148.7 \pm 32.2$ & $151.2 \pm 23.6$ & 1.966 & \\
\hline Left flexion $(\% \mathrm{BW})$ & $119.9 \pm 22.1$ & $158.6 \pm 17.8$ & $135.9 \pm 29.4$ & $174.6 \pm 11.5$ & $14.482^{* * *}$ & $1<3,2<4$ \\
\hline Bilateral balance ratio for extensor $(\%)$ & $12.7 \pm 7.6$ & $8.6 \pm 7.2$ & $7.6 \pm 4.4$ & $6.8 \pm 3.3$ & 2.214 & 1.433 \\
\hline Bilateral balance ratio for flexor $(\%)$ & $6.3 \pm 4.1$ & $11.1 \pm 7.5$ & $11.6 \pm 10.8$ & $7.6 \pm 5.2$ & & $3.352^{*}$ \\
\hline H:Q ratio for the right $(\%)$ & $50.5 \pm 7.4$ & $57.4 \pm 7.1$ & $58.4 \pm 7.1$ & $55.8 \pm 5.8$ & $1<3$ \\
\hline H:Q ratio for the left (\%) & $51.1 \pm 6.5$ & $59.0 \pm 6.8$ & $53.3 \pm 8.6$ & $56.9 \pm 4.8$ & $3.380^{*}$ & \\
\hline \hline
\end{tabular}

$\mathrm{FCRP}^{1}$, forwards in college rugby players; $\mathrm{BCRP}^{2}$, backs in college rugby players; $\mathrm{FPRP}^{3}$, forwards in professional rugby players; $\mathrm{BPRP}^{4}$, backs in professional rugby players; $\mathrm{N} \cdot \mathrm{m}$, newton meter; $\mathrm{H}: \mathrm{Q}$ hamstring:quadriceps.

${ }^{*} p<.05^{* *} p<.01^{* *} p<.001$ 
것으로 나타났다. 우굴근 절대값은 $\mathrm{FPRP}$ 그룹이 $\mathrm{FCRP}$, $\mathrm{BCRP}$ 그룹보다 높은 것으로 나타났고, 상대값은 $\mathrm{BPRP}$, $\mathrm{BCRP}, \mathrm{FPRP}$ 그룹이 $\mathrm{FCRP}$ 그룹보다 높게 나타났다. 좌 신근, 좌굴근의 절대값에서는 그룹간 차이가 나타나지 않 았으나, 좌신근, 좌굴근의 상대값에서는 $\mathrm{BPRP}$ 그룹이 다 른 그룹에 비해 높은 것으로 나타났다. 굴근과 신근 좌우 비는 그룹간 차이가 나타나지 않았으며, 우측 굴곡과 신 전 비율은 $\mathrm{FPRP}$ 그룹이 $\mathrm{FCRP}$ 그룹보다 높은 것으로 나 타났다. 좌측 굴곡과 신전 비율은 그룹간 유의한 차이가 나타나지 않았다.

\section{포지션별 등속성 허리 근기능의 변화}

대학 및 실업 럭비선수들의 포지션별 허리 등속성 근 기능을 측정한 결과는 〈Table 5〉와 같다. 허리신근 절대 값은 유의한 차이가 나타나지 않았으나, 상대값 $(p<.002)$ 은 유의한 차이가 나타났다. 허리굴근 절대값 $(p<.001)$ 과 상대값 $(p<.035)$ 은 유의한 차이가 나타났고, 허리굴/ 신비에서는 유의한 차이가 나타나지 않았다. 사후 검증
결과 허리신근 절대값은 그룹간 차이가 나타나지 않았 으나, 상대값은 $\mathrm{BPRP}$ 그룹이 $\mathrm{FCRP}, \mathrm{FPRP}$ 그룹보다 높 은 것으로 나타났다. 허리굴근 절대값은 $\mathrm{FPRP}, \mathrm{FCRP}$ 그룹이 $\mathrm{BCRP}$ 그룹보다 높은 것으로 나타났고, 상대값은 $\mathrm{BPRP}$ 그룹이 $\mathrm{FCRP}$ 그룹보다 높은 것으로 나타났다. 허 리굴/신비에서는 그룹간 차이가 나타나지 않았다.

\section{포지션별 무산소성 페달링 파워의 변화}

대학 및 실업 럭비 선수들의 포지션별 윈게이트 검사 결과는 〈Table 6)과 같다. 최대파워 (peak power)와 평 균파워 (average power)의 절대값( $p<.001)$ 과 상대값 ( $p<.001)$ 은 모든 그룹에서 통계적으로 유의한 차이가 나 타났다. 사후 검증 결과 최대파워 절대값은 $\mathrm{FPRP}$ 그룹 이 다른 모든 그룹에 비해 높은 것으로 나타났고, 상대값 은 $\mathrm{BPRP}, \mathrm{FPRP}$ 그룹이 $\mathrm{BCRP}, \mathrm{FCRP}$ 그룹보다 높은 것 으로 나타났다. 평균파워 절대값은 $\mathrm{FPRP}$ 그룹이 가장 높 은 것으로 나타났고, 상대값은 $\mathrm{BPRP}$ 그룹이 가장 높은 것으로 나타났다.

Table 5. Isokinetic trunk strength at $30 \% \mathrm{sec}$

$($ Mean \pm SD)

\begin{tabular}{lcccccc}
\hline \hline Variable & FCRP $^{1}$ & BCRP $^{2}$ & FPRP $^{3}$ & BPRP $^{4}$ & F-value & Scheffe \\
\hline Extension $(\mathrm{N} \cdot \mathrm{m})$ & $376.4 \pm 79.3$ & $361.3 \pm 75.2$ & $394.6 \pm 70.4$ & $388.9 \pm 70.8$ & .624 & \\
\hline Extension $(\% \mathrm{BW})$ & $344.0 \pm 79.4$ & $421.7 \pm 85.6$ & $360.5 \pm 64.0$ & $450.5 \pm 63.7$ & $5.711^{*}$ & $1,3<4$ \\
\hline Flexion $(\mathrm{N} \cdot \mathrm{m})$ & $313.3 \pm 49.2$ & $251.1 \pm 55.9$ & $328.2 \pm 56.0$ & $292.8 \pm 30.7$ & $6.852^{* * *}$ & $2<1,3$ \\
\hline Flexion $(\% \mathrm{BW})$ & $284.5 \pm 39.0$ & $293.1 \pm 68.4$ & $298.8 \pm 44.0$ & $340.6 \pm 25.0$ & $3.088^{*}$ & $1<4$ \\
\hline F: : ratio $(\%)$ & $86.1 \pm 21.2$ & $71.4 \pm 17.4$ & $84.2 \pm 13.6$ & $76.8 \pm 10.7$ & 2.549 & \\
\hline
\end{tabular}

$\mathrm{FCRP}^{1}$, forwards in college rugby players; $\mathrm{BCRP}^{2}$, backs in college rugby players; $\mathrm{FPRP}^{3}$, forwards in professional rugby players: $\mathrm{BPRP}^{4}$, backs in professional rugby players; $\mathrm{N} \cdot \mathrm{m}$, newton meter; $\mathrm{F}: \mathrm{E}$ ratio, flexor:extensor ratio. ${ }^{*} p<.05^{* *} p<.01^{* *} p<.001$

Table 6. The different of pedaling power/wingate test

$(\mathrm{Mean} \pm \mathrm{SD})$

\begin{tabular}{lcccccc}
\hline \hline Variable & FCRP $^{1}$ & BCRP $^{2}$ & FPRP $^{3}$ & BPRP $^{4}$ & F-value & Scheffe \\
\hline Peak power $(\mathrm{W})$ & $976.2 \pm 93.1$ & $776.8 \pm 93.9$ & $1317.5 \pm 148.5$ & $1073.3 \pm 132.4$ & $54.389^{* * *}$ & $2<1,4<3$ \\
\hline Peak power $(\mathrm{W} / \mathrm{kg})$ & $8.9 \pm 0.8$ & $9.1 \pm 0.9$ & $12.0 \pm 1.0$ & $12.4 \pm 0.5$ & $62.646^{* * *}$ & $1,2<3,4$ \\
\hline Average power $(\mathrm{W})$ & $703.7 \pm 58.9$ & $589.2 \pm 73.7$ & $1044.5 \pm 81.5$ & $894.4 \pm 98.8$ & $96.916^{* * *}$ & $2<1<4<3$ \\
\hline Average power $(\mathrm{W} / \mathrm{kg})$ & $6.4 \pm 0.6$ & $6.9 \pm 0.8$ & $9.5 \pm 0.8$ & $10.4 \pm 0.5$ & $121.693^{* * *}$ & $1,2<3<4$ \\
\hline \hline
\end{tabular}

$\mathrm{FCRP}^{1}$, forwards in college rugby players; $\mathrm{BCRP}^{2}$, backs in college rugby players; $\mathrm{FPRP}^{3}$, forwards in professional rugby players: $\mathrm{BPRP}^{4}$, backs in professional rugby players.

${ }^{*} p<.05^{* *} p<.01^{* *} p<.001$ 


\section{논 의}

럭비선수들의 포지션에 따른 신체구성을 비교한 본 연 구 결과 BMI, FFM, \% Fat는 백스 보다 포워드가 모두 높 은 수치를 보였고, 통계적으로 유의한 차이가 나타났다. 이러한 차이는 럭비 경기 중 포워드가 스크럼(scrum)을 만들거나 상대팀과 맞붙은 체력대결구도에서 공격적인 역할을 수행하기 때문에 근육량이 많고 체격이 우수하며, 백스 포지션은 스피드와 민첩성으로 상대팀을 피해 득점 을 성공 해야함으로 체지방, $\mathrm{BMI}$ 가 낮은 것으로 나타났 다고 생각된다. 다수의 선행 연구에서도 포워드가 BMI, FFM, \%Fat이 높은 것으로 보고하였고(O'Connor, 1996; Meir et al., 2001; 원광희 등, 2003; Till, 2017), 팀의 승 패를 위해서는 포지션 특성에 맞는 체격과 체력이 뒷받침 되어야 하며, 포지션에 따른 트레이닝과 기술능력을 향상 시키는 과학적인 훈련 프로그램이 필요하다고 제시하였다.

럭비는 최대근력, 근파워 등이 요구되는 종목으로 벤치 프레스, 스쿼트, 악력, 40 야드 스프린트 달리기 등과 같은 훈련을 통해 선수들에 경기력 관련 체력과 기술을 향상 시킨다(Bompa \& Claro, 2015; Fry \& Kraemer, 1991). 본 연구의 경기력 관련 체력 분석에서는 스쿼트와 악력이 그룹간 유의한 차이를 보이지 않았지만, 포워드가 백스보 다 높은 경향을 보였다. 벤치프레스에서는 그룹간에 통 계적으로 유의한 차이가 나타났으며, 실업팀의 포워드와 백스가 대학 선수들보다 높은 수치를 보였다. 이러한 결 과는 대학팀의 포워드와 백스 모두 상체근력 향상을 위한 훈련 프로그램 적용이 반드시 필요하다는 것을 제시하고 있다. Monica et al. (2016)은 럭비의 포워드 선수들이 스 쿼트와 벤치프레스 수치가 높았으며, 프로팀의 최대근력 이 대학팀보다 높아 경기력이 우수한 것으로 보고하였다 (Till et al., 2017). 하지만 Appleby et al.(2012)의 연구 결과에서는 같은 연령의 백스와 포워드는 최대근력이 비 슷하다고 보고하여 본 연구결과와는 차이를 보였다. 하 지만 우리나라 럭비 대회는 대학과 실업팀이 같은 경기 를 진행해야 함으로 대학이 우수한 경기력을 보여주기 위 해서는 포지션에 따른 최대근력 향상이 필요한 것으로 사 료된다.

등속성 장비 (isokinetic device)는 주동근(agonist)과 길항근(antagonist)의 상호 협력적 움직임과 효율성을 측정하고, 발달시키기에 적합한 훈련 장비이다(Willson et al., 2006; Davies, 1993; Mendiguchia et al., 2015). 등속성 무릎 근기능 측정 결과 우신근, 우굴근, 좌신근, 좌굴근의 상대값 및 좌우측 굴곡과 신전 비율은 포워드 보다 백스 포지션이 높은 수치로 유의하게 나타났다. 럭 비 선수 포지션에 따른 등속성 근기능에 관련한 선행연구 에서는 포워드가 백스보다 등속성 무릎 근력이 우세하다 고 보고하였다(Brown et al., 2014; James et al., 2005). 선행연구와는 다른 결과를 나타냈지만, 절대값에서는 포 워드가 백스보다 굴곡과 신전에서 높은 수치의 경향을 보 였다. 이러한 결과는 포워드가 바인딩 (binding) 동작과 라인아웃(lineout)시 리프터(lifters) 자세를 취하기 위해 대퇴사두근과 햄스트링의 최 대근력 사용빈도가 높기 때 문이다. 그러므로 실업팀보다 무릎 근기능이 약한 FCRP, $\mathrm{BCRP}$ 는 좌우측 굴곡과 신전의 비율을 높일 수 있는 하 지 트레이닝과 반복적인 기술훈련을 적용하여 운동수행 능력을 향상시킨다면, 실업팀과의 경기시 승패를 좌우할 수 있을 것이라 생각된다.

본 연구에서 허리 등속성 근기능을 측정한 결과, 백스 포지션이 허리 신전·굴곡 상대값에서 유의한 차이가 나타 났지만, 선행연구에서는 태클(tackle), 스크럼(scrum), 몰 (maul) 등 상황에서 코어 근력과 햄스트링 근력을 유 지 하면서 상대방을 밀치고 버텨야 하기 때문에 포워드 의 최대근력이 높다고 보고하였다 (Quarrie \& Wilson, 2000). 선행연구와 본 연구결과와의 차이는 나타났지만, 절대값에서는 포워드의 수치가 높고, 상대값에서는 백스 가 높으므로 포지션에 따른 등속성 허리 근기능 비교는 서로 다른 경향을 보인 것으로 생각된다. 그러므로, 허리 근력은 협응력, 가동성 및 움직임의 방향 등 경기력과 밀 접한 상관관계가 높은 체력이므로, 특이적이고 효율적인 트레이닝을 적용한다면 경기력에 긍정적인 영향을 미칠 것으로 생각된다.

윈게이트 검사는 무산소성 에너지 시스템을 동원한 무 산소성 파워를 정량적으로 평가 할 수 있고, 본 연구에서 는 $\mathrm{PP}$ 와 $\mathrm{AP}$ 모두 그룹간 유의한 차이가 나타났다. 포워 드가 체중이 많이 나감에도 불구하고 $\mathrm{PP}$ 와 $\mathrm{AP}$ 가 높다 는 것은 무산소성 에너지 대사능력과 속근(fast twitch fiber)의 동원율이 높다고 할 수 있다. Coppin et al. (2012) 은 20 세 운동선수의 윈게이트 검사 결과 $\mathrm{PP}$ 가 $12.8 \mathrm{~W} / \mathrm{kg}$, $\mathrm{AP}$ 가 $9.2 \mathrm{~W} / \mathrm{kg}$ 으로 기준치를 제시하였고, 본 연구의 $\mathrm{FPRP}$ 와 $\mathrm{BPRP}$ 의 무산소성 파워는 선행연구의 기준치 에 도달하였으나, $\mathrm{FCRP}$ 와 $\mathrm{BCRP}$ 는 기준 이하의 파워 
를 보였다. 무산소성 파워가 높은 선수들은 근파워 또한 높으며, 근파워는 럭비 종목의 모든 포지션에서 절대적으 로 필요한 체력요인이라고 보고한 선행연구(Bompa \& Claro, 2015; Jones et al., 2015)와 같이 FCRP와 BCRP 는 최대근력과 스피드를 향상 시킬 수 있는 트레이닝을 적용하고, 무산소성 파워를 향상시킨다면 경기력에 긍정 적인 영향을 미칠 것으로 생각된다.

\section{결론 및 제언}

본 연구에서는 대학과 실업 럭비팀의 포지션에 따른 최대근력, 등속성 무릎과 허리 근력 및 무산소성 파워 비 교를 위해 26 명의 대학선수와 28 명의 프로 선수들을 대 상으로 실험을 수행하였다.

실업팀 포워드와 백스가 근육량, 최대근력, 등속성 무 릎과 허리 근력 그리고 무산소성 파워 모두 대학팀 선수 들보다 높게 나타났다. 특히, 실업팀의 백스 선수들이 포 워드 선수들보다 전반적으로 높은 최대근력과 무산소성 파워를 나타냈다. 이러한 결과들을 종합해 볼 때, 대학의 모든 포지션과 실업팀의 포워드 선수들은 최대근력과 무 산소성 파워와 같은 경기력 관련 체력 요인을 향상시키기 위한 체계적이고 과학적인 훈련 프로그램이 제공되어야 한다고 사료된다.

\section{참고문헌}

원광희, 이길우, 장지훈. (2003). 럭비선수의 포지션별 유산소성 운동능력, 무산소성 파워 및 혈중지질 성분에 있어서의 차 이. 한국스포츠학회지, 1(1), 249-256.

Appleby, B., Newton, R. U., \& Cormie, P. (2012). Changes in Strength over a 2-Year Period in Professional Rugby Union Players. Journal of Strength and Conditioning Research, 26(9), 2538-2546.

Bompa, T., \& Claro, F. (2015). Periodization in rugby. Meyer \& Meyer Verlag.

Brown, S. R., Brughelli, M., Griffiths, P. C., Cronin, J. B. (2014). Lower-Extremity Isokinetic Strength Profiling in Professional Rugby League and Rugby Union. International Journal of Sports Physiology and Performance, 2014(9), 358-361.

Comfort, P., Graham-Smith, P., Matthews, M. J., \& Bamber, C.
(2011). Strength and power characteristics in English elite rugby league players. The Journal of Strength \& Conditioning Research, 25(5), 1374-1384.

Coppin E., Heath E. M., Bressel E., Wagner D.R.. (2012). Wingate anaerobic test reference values for male power athletes. Int J Sports Physiol Perform, 7, 232-236.

Cunniffe, B., Proctor, W., Baker, J. S., \& Davies, B. (2009). An evaluation of the physiological demands of elite rugby union using global positioning system tracking software. The Journal of Strength \& Conditioning Research, 23(4), 1195-1203.

Davies, P. R., \& Kaar, G. (1993). High thoracic disc prolapse in a rugby player: The first reported case. British Journal of Sports Medicine, 27(3), 177-178.

Duthie, G., Pyne, D., \& Hooper, S. (2003). Applied physiology and game analysis of rugby union. Sports Medicine, 33(13), 973-991.

Dymond, C., Flanagan, E. P., \& Turner, A. P. (2011). The relationship between maximal strength and plyometric ability in rugby players. In ISBS-Conference Proceedings Archive (Vol. 1, No. 1).

Franchini, E., Del Vecchio, F. B., Matsushigue, K. A., \& Artiol, G. C. (2011). Physiological profiles of elite Judo athletes. Sports Medicine, 41(2), 147-166.

Fry, A. C., \& Kraemer, W. J. (1991). Physical performance characteristics of American collegiate football players. The Journal of Strength \& Conditioning Research, 5(3), 126-138.

James, N., Mellalieu, S., Jones, N. (2005). The development of position-specific performance. Journal of Sports Sciences, 2005(23), 63-72.

Jones, M. R., West, D. J., Crewther, B. T., Cook, C. J., \& Kilduff, L. P. (2015). Quantifying positional and temporal movement patterns in professional rugby union using global positioning system. European Journal of Sport Science, 15(6), 488-496

La Monica, M. B., Fukuda, D. H., Miramonti, A. A., Beyer, K. S., Hoffman, M. W., Boone, C. H., Tanigawa, S., Wang, R., Church, D. D., Stout, J. R. Hoffman, J. R. (2016). Physical differences between forwards and backs in American collegiate rugby players. Journal of Strength and Conditioning Research, 30(9), 2382-2391.

Lindsay, A., Draper, N., Lewis, J., Gieseg, S. P., \& Gill, N. (2015). Positional demands of professional rugby. European Journal of Sport Science, 15(6), 480-487.

L. Quarrie, K., \& Wilson, B. D. (2000). Force production in the 
rugby union scrum. Journal of Sports Sciences, 18(4), 237246.

Meir, R., Newton, R., Curtis, E., Fardell, M., \& Butler, B. (2001). Physical fitness qualities of professional rugby league football players: Determination of positional differences. The Journal of Strength \& Conditioning Research, 15(4), 450-458.

Mendiguchia, J., Martinez Ruiz, E., Morin, J. B., Samozino, P., Edouard, P., Alcaraz, P. E., ... \& Mendez Villanueva, A. (2015). Effects of hamstring-emphasized neuromuscular training on strength and sprinting mechanics in football players. Scandinavian Journal of Medicine \& Science in Sports, 25(6), 621-629.

O'Connor, D. (1996). Physiological characteristics of professional rugby league players. Strength and Conditioning Coach, $4(1), 21-26$.

Pienaar, C., \& Coetzee, B. (2013). Changes in selected physical, motor performance and anthropometric components of university-level rugby players after one microcycle of a combined rugby conditioning and plyometric training program. The Journal of Strength \& Conditioning Research,
27(2), 398-415.

Serresse, O., Ama, P. F., Simoneau, J. A., Lortie, G., Bouchard, C., \& Boulay, M. R. (1989). Anaerobic performances of sedentary and trained subjects. Canadian Journal of Sport Sciences (Journal Canadien des Sciences du Sport), 14(1), 46-52.

Till, K., Scantlebury, S., \& Jones, B. (2017). Anthropometric and physical qualities of elite male youth rugby league players. Sports Medicine, 47(11), 2171-2186.

Ueno, Y., Watai, E., \& Ishii, K. (2011, November). Aerobic and anaerobic power of rugby football players. In Science and Football: Proceedings of the First World Congress of Science and Football Liverpool, 13th-17th April 1987. Routledge.

Willson, J. D., Ireland, M. L., \& Davis, I. (2006). Core strength and lower extremity alignment during single leg squats. Medicine \& Science in Sports \& Exercise, 38(5),945-952.

Zagatto, A. M., Beck, W. R., \& Gobatto, C. A. (2009). Validity of the running anaerobic sprint test for assessing anaerobic power and predicting short-distance performances. The Journal of Strength \& Conditioning Research, 23(6), 18201827.

\section{대학 및 실업 럭비선수들의 포지션에 따른 최대근력, 등속성 무릎과 허리 근기능 및 무산소성파워 비교 연구}

\section{조영현 · 박지희 · 김지은 · 유주인 · 김영표 - 서태범(제주대학교 체육학과)}

〔목적〕 본 연구는 대학과 실업팀 럭비선수들의 포지션에 따른 최대근력, 등속성 무릎과 허리 근기능 및 무 산소성파워를 비교하는 것이다. 〔방법) 총 54명의 럭비선수로 대학 럭비선수 포워드 그룹(FCRP, $n=10$ ), 대학 럭비선수 백스 그룹(BCRP, $n=16$ ), 실업팀 럭비선수 포워드 그룹(FPRP, $n=16)$, 실업팀 럭비선수 백스 그룹(BPRP, $n=12$ )으로 구분하였다. 체력관련요인으로 스쿼트, 벤치프레스, 양쪽악력으로 구성하였 으며, 무릎 및 허리 등속성 근기능 검사는 Humac Norm 장비를 사용하여 측정하였다. 무산소성 페달링 파워 는 Wingate로 측정 및 분석하였다. 〔결과) 스쿼트의 절대값과 상대적 값과 양쪽 악력은 통계적으로 유의한 차이가 없었지만, 벤치 프레스는 다른 그룹에 비해 FPRP와 BPRP에서 유의미하게 높았다. 등속성 무릎과 허 리 신전과 굴곡에서는 $\mathrm{FCRP}$ 와 $\mathrm{BCRP}$ 에 비해 $\mathrm{FPRP}$ 와 $\mathrm{BPRP}$ 에서 높았고, 사후검사 결과 $\mathrm{BPRP}$ 에서 가장 높게 나타났다. 무산소성 페달링 파워 또한 $\mathrm{BPRP}$ 에서 가장 높았다. 〔결론) 본 연구 결과는 대학 럭비팀선수 들과 프로팀의 포워드 선수들은 최대근력, 등속성 근기능 및 무산소성 파워 향상을 위한 체계적이고, 과학적인 훈련 프로그램이 제공되어야 한다는 정보를 제시한다.

주요어: 럭비, 등속성 근기능, 무산소성파워, 최대근력 